\title{
Methylation Pattern of the SOCS3 and IL6R Promoters in Rheumatoid Arthritis
}

\author{
Marek Cieśla $\mathbb{D}^{1},{ }^{1}$ Bogdan Kolarz $\mathbb{D}^{1},{ }^{1}$ Maria Majdan, ${ }^{2}$ and Dorota Darmochwat-Kolarz ${ }^{1}$ \\ ${ }^{1}$ Institute of Medical Sciences, Medical College, University of Rzeszow, 35-959 Rzeszow, Poland \\ ${ }^{2}$ Department of Rheumatology and Connective Tissue Diseases, Medical University of Lublin, 20-090 Lublin, Poland \\ Correspondence should be addressed to Marek Cieśla; ciesla_marek@wp.pl
}

Received 25 September 2019; Revised 30 November 2019; Accepted 8 February 2020; Published 31 March 2020

Academic Editor: Andrew S. Day

Copyright (C) 2020 Marek Cieśla et al. This is an open access article distributed under the Creative Commons Attribution License, which permits unrestricted use, distribution, and reproduction in any medium, provided the original work is properly cited.

Interleukin-6 (IL-6) plays an essential function in the development of rheumatoid arthritis (RA), mainly through its proinflammatory effect, which may lead to joint destruction. The genes encoding IL-6 receptor (IL6R) and suppressor of cytokine signaling 3 (SOCS3) play a key role in the IL-6 signaling pathway, but their epigenetic regulation remains unclear. The aim of the study was to investigate how the presence of methylation in the SOCS3 and IL6R promoters is associated with the morbidity and severity of RA. A total of 146 unrelated individuals, 122 with RA and 24 healthy controls, were enrolled in the study. All subjects were genotyped with regard to the rs4969168 and rs4969170 polymorphisms in the SOCS3 gene and the rs2228145 and rs4129267 polymorphisms in IL6R. The methylation study included 52 patients with RA and 24 healthy controls. Qualitative real-time methylation-specific PCR was used to evaluate methylation status. We found no differences between patients and healthy controls in the methylation pattern in the IL6R and SOCS3 promoter regions and in variants frequency. The methylation profiles of the SOCS3 and IL6R promoters do not support the hypothesis that the genes SOCS3 and IL6R involved in the JAK-STAT signaling pathway are epigenetically deregulated in whole blood.

\section{Introduction}

Rheumatoid arthritis (RA) is a chronic inflammatory disease that leads to joint destruction $[1,2]$. Single nucleotide polymorphisms (SNPs) are considered important genetic risk factors in the development of RA [3, 4]. Apart from SNPs, epigenetic modifications such as DNA methylation have been reported as an important factor related to the development of a number of diseases [5]. The presence of DNA methylation manifested by the presence of 5-methylcytosine in the $\mathrm{CpG}$ dinucleotide is considered an important mechanism regulating gene expression. In most cases, the presence of a large percentage of $\mathrm{CpGs}$ in the promoter region is associated with constant gene silencing, but recent reports have demonstrated that the methylation pattern in regulatory regions such as transcription factor binding sites or gene enhancers may play a critical role in this regulation $[5,6]$. Despite these findings, molecular mechanisms involved in RA pathogenesis are still unclear [3].
Interleukin-6 (IL-6) is a cytokine responsible for both inflammation and hematopoiesis. IL-6 stimulates the production of hepatic acute-phase proteins such as C-reactive protein (CRP) and plays a critical function in joint destruction caused by inflammation, thereby affecting RA development [7]. The IL- 6 signaling pathway is mediated by the membrane-bound IL-6 receptor (IL6R), which consists of two glycoproteins: IL6R $\alpha$ and $\beta$ (gp130). The latter is expressed by most cells, while expression of IL6R $\alpha$ on the cell surface is limited [8]. However, proteolysis of IL6R or alternative mRNA splicing may generate a soluble form of IL6R (sIL6R). In a transsignaling process, activated sIL6R binds to the gp130 membrane subunit and may allow various cells to respond to IL-6 [9]. According to the ENSEMBL database (https://www.ensembl.org, November 2018) [10], the IL6R gene is situated on the first chromosome in the position from $154,405,193$ to $154,469,450077$ in reference to assembly GRch38 on the forward strand. The SNP Asp358Ala in the IL6R gene $(A>C$; rs2228145) is 
associated with various diseases, such as asthma, coronary heart disease, or type 1 diabetes. In the case of RA, the $\mathrm{C}$ allele in this variant reduces susceptibility to the disease [11]. The SNP with rs4129267 is located at intron 8 (1q21.3) in the IL6R gene and has previously been reported to be associated with asthma susceptibility in Europeans [12].

The suppressor of cytokine signaling 3 (SOCS3) gene is located on chromosome 17 on the reverse strand in location $78,356,778-78,360$. With regard to the immune response, this gene participates in negative regulation of the inflammatory process, mainly through negative regulation of the JAK-STAT cascade (ENSEMBL database (https://www.ensembl.org, November 2018) [10]. The SNP with rs4969168 in the SOCS3 gene is located in the $3^{\prime} \mathrm{UTR}$ region, while SOCS3 rs4969170 is located in the promoter. Both variants have been studied for an association with various diseases, such as atopic dermatitis [13], HCV treatment-induced neutropenia and thrombocytopenia [14], and with insulin resistance in chronic hepatitis $C$ patients [15], but only the SOCS3 rs4969170 polymorphism has been found to be linked to these conditions. There is insufficient information regarding possible methylation changes in both the IL6R and SOSC3 genes in RA; only Liu et al. have reported a single CpG potentially associated with the RA phenotype in Supplementary Material, but this single methylation locus was not finally reported as a genetic risk factor [16].

Given that both SOCS3 and IL6R play a key role in the IL-6 signaling pathway, the main aim of the current study was to investigate whether the methylation patterns of SOCS3 and IL6R promoters are associated with the morbidity and severity of RA. A secondary challenge was to verify the hypothesis that SNPs in these genes may be considered genetic risk factors associated with rheumatoid factor- (RF-) positive patients.

\section{Materials and Methods}

2.1. Patients. A total of 146 unrelated individuals, 122 with RA and 24 healthy controls, were enrolled in the study. The Medical University in Lublin Ethics Committee approved the study (protocol number KE-0254/7/2016), and the patients provided written informed consent.

Whole blood and serum samples were collected and stored at $-80^{\circ} \mathrm{C}$ until analysis. The study included two approaches-epigenetic and genetic. Epigenetic assessments involved analysis of SOCS3 and IL6 promoters methylation in subjects with high disease activity and patients in remission, as well as healthy controls. Genetic assessments involved all individuals enrolled to the study.

\subsection{DNA Extraction and Bisulfide Conversion. DNA was} extracted from $200 \mu \mathrm{l}$ of frozen whole blood according to the manufacturer's protocol using the GeneMATRIX Quick Blood DNA Purification Kit (Eurx, Poland). A $1 \mu \mathrm{g}$ DNA sample was converted by sodium bisulfite using the EZ DNA Methylation Gold Kit (Zymo Research, USA) according to the manufacturer's recommendations, but the elution volume was increased to $50 \mu \mathrm{l}$. DNA was stored at $-80^{\circ} \mathrm{C}$ until further analysis.
2.3. Methylation Study. From a total of $122 \mathrm{RA}$ in the methylation study were selected 52 patients with RA as well as 24 healthy controls. Patients were chosen based on disease activity score 28 (DAS28): only individuals with high disease activity (DAS28 > 5.1; $n=30$ ) and in remission (DAS28 $\leq 2.6$; $n=22$ ) were enrolled.

The promoter regions were found in the Eukaryotic Promoter Database (EPD, https://epd.vital-it.ch, November 2017) [17]. Using the EPD motif tool (based on JASPAR core 2018 vertebrates), in the SOCS3 promoter region we found a predictive binding site for transcriptional repressor CTCF (the cut off $p$ value was 0.0001 ) at position -874 with respect to the transcription start site (TSS). Primers complementary to the methylated sequence flanked this position at locations from -961 to -835 in reference to TSS. In the IL6R promoter, we found a CpG-rich region downstream of TSS and decided to locate the primers from -169 to -78 . In this target region we found predictive binding sites for transcription factors from the family of interferon regulatory factors, IRF4 and IRF5 (the cut off $p$ value was 0.001 ), which may play a significant role in regulation of the immune system [18]. Primers were designed using MethPrimer Software, version 1.0 [19]. Their sequences are presented in Table 1. The ability to amplify specific sequences was evaluated using fully methylated and unmethylated DNA controls (EpiTect PCR Control DNA Set, Qiagen, Germany). PCR products were visualized in a $2 \%$ agarose gel.

All samples had previously been evaluated for suitability for epigenetic testing by amplifying a DNA region free of $\mathrm{CpG}$ sites in the beta-actin gene $(A C T B)$. Samples were considered suitable for further analysis when the cycle threshold $(\mathrm{Ct})$ value was below 30. Qualitative real-time methylation-specific PCR (q-MSP) was used to analyze the methylation status. The methylation status of the promoters was evaluated using primers complementary to the methylated target sequence. The Q-MSP reaction contained $500 \mathrm{nM}$ of each primer for SOCS3, $300 \mathrm{nM}$ for both $I L 6 R$ and $A C T B$, and $3 \mu \mathrm{l}$ or $4 \mu \mathrm{l}$ bisulfidetreated DNA for SOCS3 or IL6R, respectively. The reaction was performed using ExiLENT SYBR Green master mix (EXIQON, Denmark) in the COBAS z480 Real-Time PCR System under the thermal cycling conditions given in the mix manual, in 50 amplification cycles and with an annealing/elongation step at $63^{\circ} \mathrm{C}$ or $62^{\circ} \mathrm{C}$ for SOCS3 and IL6R, accordingly, for $1 \mathrm{~min}$. This was followed by a PCR melt curve analysis. All reaction plates contained a positive control sample with $1 \%$ methylated sequences in $99 \%$ unmethylated sequences. The data were analyzed using the Absolute Quantification module (LightCycler 480 SW, version 1.5.1.62 SP2-UDF v.2.0.0, Roche, Germany), with the maximum second derivative selected as the calculation model. If the $\mathrm{Ct}$ of the sample was lower than the $\mathrm{Ct}$ of the positive control, the sample was assessed as positive for methylation.

2.4. Genotyping. Genotypes of SOCS3 rs4969168 (G>A, assay ID: C__1706397_20, Thermo Fisher Scientific, USA) and rs4969170 (G>A, assay ID: C_29949384_10, Thermo Fisher Scientific, USA) and of IL6R rs4129267 (C>T, assay ID: C_26292282_10, Thermo Fisher Scientific, USA) and 
TABLE 1: Characteristics of primers and amplicons.

\begin{tabular}{|c|c|c|c|c|c|}
\hline Gene & Primer name & Sequence $5^{\prime} \longrightarrow 3^{\prime *}$ & $\begin{array}{l}\text { Amplicon } \\
\text { size [bp] }\end{array}$ & $\begin{array}{c}\text { Amplicon location } \\
\text { with reference to } \\
\text { assembly GRCh38 } \\
\text { [chromosome: } \\
\text { start: end: strand] }\end{array}$ & $\begin{array}{c}\text { Primer } \\
\text { complementary to } \\
\text { methylated/ } \\
\text { unmethylated } \\
\text { sequences }\end{array}$ \\
\hline$A C T-B$ & $\begin{array}{c}\text { ACTB sense } \\
\text { ACTB antisense }\end{array}$ & $\begin{array}{c}\text { GGTGGTGATGGAGGAGGTTTAG } \\
\text { CCCTTAAAAATTACAAAAACCACAACC }\end{array}$ & 115 & $\begin{array}{l}7: 5532117: \\
5532232:-1\end{array}$ & $\begin{array}{l}\text { Independent of } \\
\text { methylation status }\end{array}$ \\
\hline \multirow{2}{*}{ SOCS3 } & $\begin{array}{c}\text { SOCS3_- } \\
\text { methyl_sense } \\
\text { SOCS3_- } \\
\text { methyl_antisense }\end{array}$ & $\begin{array}{c}\text { GTGGAACGATGGTTTTAATTTACG } \\
\text { ATTCCCGCAAATCCCTAACG }\end{array}$ & 126 & $\begin{array}{c}17: 78360912: \\
78361038: 1\end{array}$ & $\begin{array}{l}\text { Methylated } \\
\text { sequences }\end{array}$ \\
\hline & $\begin{array}{c}\text { SOCS3_- } \\
\text { unmethyl_sense } \\
\text { SOCS3_- } \\
\text { unmethyl_antisense }\end{array}$ & $\begin{array}{l}\text { GGTGGAATGATGGTTTTAATTTATG } \\
\text { ATTCCCACAАATCССТАACATAC }\end{array}$ & 127 & $\begin{array}{c}17: 78360911: \\
78361038: 1\end{array}$ & $\begin{array}{l}\text { Unmethylated } \\
\text { sequences }\end{array}$ \\
\hline \multirow[b]{2}{*}{$I L 6 R$} & $\begin{array}{l}\text { IL6R_methyl_sense } \\
\text { IL6R_- } \\
\text { methyl_antisense }\end{array}$ & $\begin{array}{l}\text { CGTATTTTGGGACGGTTTAGAGAC } \\
\text { CACATAACTCAAAACGACGAACG }\end{array}$ & 91 & $\begin{array}{c}1: 154405299: \\
154405390: 1\end{array}$ & $\begin{array}{l}\text { Methylated } \\
\text { sequences }\end{array}$ \\
\hline & $\begin{array}{l}\text { IL6R_- } \\
\text { unmethyl_sense } \\
\text { IL6R_- } \\
\text { unmethyl_antisense }\end{array}$ & $\begin{array}{l}\text { TTGTATTTTGGGATGGTTTAGAGATG } \\
\text { TCACACATAACTCAAAACAACAAACAAT }\end{array}$ & 95 & $\begin{array}{c}1: 154405298: \\
154405393: 1\end{array}$ & $\begin{array}{l}\text { Unmethylated } \\
\text { sequences }\end{array}$ \\
\hline
\end{tabular}

* CpG sites in primer sequence are in bold.

rs2228145 (A>C, assay ID: C__16170664_10, Thermo Fisher Scientific, USA) were ascertained by the allelic discrimination test using a TaqMan genotyping assay and the Endpoint Genotyping module of the COBAS z480 RealTime PCR System (LightCycler 480 SW, version 1.5.1.62 SP2-UDF v.2.0.0, Roche, Germany).

2.5. Antibody Testing. Anticitrullinated protein antibodies (ACPA; DiaMetra, Italy) and RF (TestLine Clinical Diagnostics) were determined in serum using an enzyme-linked immunosorbent immunoassay (ELISA) and an absorbance reader (Tecan infinite M200 Pro reader and Magellan software, version 7.1). All procedures were performed according to the manufacturer's recommendations. The reference range was up to $30 \mathrm{U} / \mathrm{ml}$ for ACPA and up to $22 \mathrm{U} / \mathrm{ml}$ for RF. Antibody titers above this range were considered positive.

2.6. Statistical Analysis. Distribution of variables was assessed by the Shapiro-Wilk W test. Quantitative values were presented as mean $\pm \mathrm{SD}$ or median [interquartile range]. Differences between two independent groups were compared with Student's $t$-test or the Mann-Whitney $U$ test. Qualitative parameters are given as numbers with percentage and were evaluated using contingency tables with a Fisher's exact test (one-sided) or a $\chi^{2}$ test with Yates's correction was used. Logistic regression was used for evaluation of the odds ratio (OR) and confidence intervals (CI). A $p$ value $<0.05$ was considered statistically significant. The analysis was performed with STATISTICA Version 13 (StatSoft Inc., USA). Linkage disequilibrium between SOCS3 rs4969168 and rs4969170 and between IL6R rs4129267 and rs2228145 was evaluated by LDlink application, version 3.6
[20]; for details please refer to Supplementary Figures S1 and S2, respectively.

\section{Results and Discussion}

3.1. Results. Characteristics of the patients with RA and healthy controls are presented in Table 2.

3.1.1. SOCS3 and IL6R Methylation. A detailed characterization of the RA groups is presented in Table 3. In the group with high disease activity, more patients were treated with steroids than in the patients in remission, which was in line in with common treatment strategies. ESR, CRP, and visual analog scores were higher, as expected, in the group with disease exacerbation than in the patients in remission.

Patients with RA and healthy controls did not differ in methylation profile for either SOCS3 or IL6R. None of the samples had a Ct value below the determined cut-off value (no methylation signals were obtained in both healthy controls and patients), thus no differences in epigenetic regulation were detected. Positive control ( $1 \%$ of DNA methylation) had a valid signal.

3.1.2. Genotyping. Detailed genotyping data, including the genetic models, are presented in Supplementary Tables S1-S8. The genotypes and alleles distribution of SOCS3 and IL6R between patients with RA $(n=122)$ and healthy controls $(n=24)$, RF-positive $(n=82)$ and RF-negative $(n=40)$, and ACPA-positive $(n=104)$ and ACPA-negative $(n=18)$ patients are given in Supplementary Tables S1 and S5, accordingly. No differences in genotypes frequency in regard to genetic models (codominant, dominant, overdominant, and recessive) were found between patients with RA and healthy controls and 
TABLE 2: Characteristics of patients with rheumatoid arthritis and healthy controls enrolled to the study.

\begin{tabular}{|c|c|c|c|}
\hline Characteristics & RA overall, $n=122$ & HC, $n=24$ & $p$ value \\
\hline Age (years) & $52.2 \pm 12.3$ & $52.9 \pm 8.6$ & 0.99 \\
\hline Females; $n(\%)$ & $103(84.4)$ & $18(75)$ & 0.41 \\
\hline Disease duration (years) & $10[3-16]$ & $\mathrm{n} / \mathrm{a}$ & $\mathrm{n} / \mathrm{a}$ \\
\hline RF-positive; $n(\%)$, & $82(67.2)$ & None & $\mathrm{n} / \mathrm{a}$ \\
\hline ACPA-positive; $n(\%)$ & $104(85.2)$ & None & $\mathrm{n} / \mathrm{a}$ \\
\hline ESR & $26[8-57.5]$ & $15[7-19]$ & 0.001 \\
\hline CRP (mg/dl) & $8.54[0.53-19.12]$ & $0.58[0.19-1.97]$ & $<0.0001$ \\
\hline DAS28 & $3.95 \pm 1.55$ & $\mathrm{n} / \mathrm{a}$ & $\mathrm{n} / \mathrm{a}$ \\
\hline Swollen joints & $1[0-4]$ & $\mathrm{n} / \mathrm{a}$ & $\mathrm{n} / \mathrm{a}$ \\
\hline Tender joints & $3[1-6]$ & $\mathrm{n} / \mathrm{a}$ & $\mathrm{n} / \mathrm{a}$ \\
\hline VAS PGA & $27[9-61]$ & $\mathrm{n} / \mathrm{a}$ & $\mathrm{n} / \mathrm{a}$ \\
\hline VAS PhGA & $20[7-49]$ & $\mathrm{n} / \mathrm{a}$ & $\mathrm{n} / \mathrm{a}$ \\
\hline
\end{tabular}

Data are presented as mean \pm SD, number (percentage), or median [interquartile range]. ACPA, anticitrullinated protein antibodies; DAS28, disease activity score 28; CRP, C-reactive protein; cDMARD, classical disease-modifying antirheumatic drugs; ESR, erythrocyte sedimentation rate; RF, rheumatoid factor; VAS PhGA, visual analog scale physician global assessments; VAS PGA, visual analog scale patient global assessments.

TABle 3: Characteristics of patients with rheumatoid arthritis included in the methylation analysis.

\begin{tabular}{|c|c|c|c|}
\hline Characteristics & High disease activity, $n=30$ & Remission, $n=22$ & $p$ value \\
\hline Age (years) & $53.6 \pm 12.3$ & $48.7 \pm 12.7$ & 0.21 \\
\hline Females; $n(\%)$ & $22(73.3)$ & $21(95.5)$ & 0.09 \\
\hline Disease duration (years) & $10[2-16]$ & $9.5[3.5-16]$ & 0.96 \\
\hline RF-positive; $n$ (\%), & $23(76.7)$ & $12(54.5)$ & 0.17 \\
\hline ACPA-positive; $n$ (\%) & $29(96.7)$ & $20(90.9)$ & 0.78 \\
\hline ESR & $54[28-67]$ & $7[2-11.5]$ & $<0.0001$ \\
\hline CRP (mg/dl) & $15.72[8.54-27.2]$ & $0.45[0.13-4.09]$ & $<0.0001$ \\
\hline VAS PGA & $67.5[52-73]$ & $8[3-9.5]$ & $<0.0001$ \\
\hline VAS PhGA & $59[49-70]$ & $5[1.5-7]$ & $<0.0001$ \\
\hline \multicolumn{4}{|l|}{ Treatment: } \\
\hline At least on methotrexate, $n(\%)$ & $23(76.7)$ & $15(68.2)$ & 0.72 \\
\hline At least on biologics, $n(\%)$ & $7(23.3)$ & $11(50)$ & 0.09 \\
\hline At least on steroids, $n(\%)$ & $23(76.7)$ & $7(31.8)$ & 0.003 \\
\hline Single-line therapy, $n(\%)$ & $4(13.3)$ & $7(31.8)$ & 0.2 \\
\hline Methotrexate, $n(\%)$ & $2(6.7)$ & $3(13.6)$ & 0.71 \\
\hline Biologics, $n(\%)$ & 0 & $1(4.5)$ & 0.88 \\
\hline Steroids, $n(\%)$ & $1(3.3)$ & 0 & 0.88 \\
\hline Other cDMARD, $n(\%)$ & $1(3.3)$ & $3(13.6)$ & 0.39 \\
\hline Double-line therapy, $n(\%)$ & $17(56.7)$ & $10(45.5)$ & 0.6 \\
\hline Methotrexate + steroids, $n(\%)$ & $13(43.3)$ & $1(4.5)$ & 0.0051 \\
\hline Methotrexate + biologics, $n(\%)$ & $2(6.7)$ & $4(18.2)$ & 0.4 \\
\hline Steroids + biologics, $n(\%)$ & 0 & $1(4.5)$ & 0.88 \\
\hline Other, $n(\%)$ & $2(6.7)$ & $4(18.2)$ & 0.4 \\
\hline Triple-line therapy, $n(\%)$ & $9(30)$ & $5(22.7)$ & 0.79 \\
\hline
\end{tabular}

Data are presented as mean \pm SD, number (percentage), or median [interquartile range]. ACPA, anticitrullinated protein antibodies; CRP, C-reactive protein; cDMARD, classical disease-modifying antirheumatic drugs; ESR, erythrocyte sedimentation rate; RF, rheumatoid factor; VAS PhGA, visual analog scale physician global assessments; VAS PGA, visual analog scale patient global assessments.

between patients divided by ACPA-positivity (Supplementary Tables S2, S4, S6, and S8). RF-positive patients had a lower frequency of genotype GA in SOCS3 rs4969168 in overdominant genetic model (Fisher's exact test $p$ value $=0.0412$, Supplementary Table S3). Other models were not showing differences between RF-positive and RF-negative patients in regard to studied SNPs.

The distribution of SOCS3 rs4969168 and rs4969170 and of IL6R rs4129267 and rs2228145 genotypes was in accordance with Hardy-Weinberg equilibrium $(p=0.33$, $p=0.72, p=0.26$, and $p=0.62$, respectively).
3.2. Discussion. The current study is the first to demonstrate that the morbidity and severity of RA are not associated with DNA methylation in the regulatory regions tested in either the IL6R or the SOCS3 genes. Here we have shown that neither genes had more intensive methylation in the promoter region than in the healthy controls (all patients had fully unmethylated DNA or below the detection limit), which may suggest that the IL- 6 signaling pathway in whole blood is regulated by other pathways. We have found only one study investigating methylation patterns in RA involving both the IL6R and SOCS3 genes [16]. Liu et al. 
reported only one CpG site in SOCS3 and four CpG sites in IL6R associated with an RA phenotype; however, these loci were not ultimately reported as genetic risk factors for RA [16]. SOCS3 negatively regulates inflammation via the transcriptional factor (TF) STAT3, especially under the influence of cytokines using gp130 receptors, such as IL-6, IL-11, and IL-27 [21]. Liu et al. [16] reported only a single CpG site about $83 \mathrm{bp}$ upstream of the beginning of our target region. We designed the primers in positions from -961 to -835 in reference to TSS, and they flanked a region that may be a binding site for TF CTCF, a multifunctional molecule involved in transcription, imprinting, and long-distance chromatin interaction. The negative correlation between CTCF binding and DNA methylation has been well demonstrated [22], and so the choice of this region in the promoter was not random. Moreover, a mechanism in which IL-6 increases the activity of DNA methyltransferase1 and leads to SOCS3 promoter hypermethylation has previously been reported in ulcerative colitis patients [23]. We believe that SOCS3 may be epigenetically regulated by DNA methylation, but it is important to find the specific region responsible for gene expression. Yoshikawa et al. [24] have described a region between -556 and -335 bp relative to TSS where hypermethylation was detected and demonstrated that this location may be a binding site for microRNA-122, leading to decreased expression of SOCS3. Binding sites for TF STAT3 are also situated at the microRNA-122 binding site, and thus binding micro-RNA may block activity of STAT3, which may prove critical for regulation of this gene. On the other hand, Yoshikawa et al. have shown only one possible mechanism of SOCS3 regulation. They worked with material from the liver and showed regulation induced by microRNA-122, which is specific for this tissue. It is possible that the use of more specific tissue material such as the synovium might provide more interesting data. Additional research on DNA methylation is unquestionably needed, but in our opinion epigenetic studies should be more targeted at interaction between DNA methylation and microRNAs, because this combination may provide more valuable data. Moreover, Isomaki et al. [25] have reported that SOCS family expression is profoundly changed in patients with RA but found that the level of gene expression was cell population and cellular compartment. With regard to SOCS3, they found increased expression of SOCS3 mainly in peripheral blood monocytes from subjects with RA relative to healthy controls. Isomäki et al. used peripheral blood mononuclear cells as working material, while we have used frozen whole blood, and although we achieved a limit of detection of about $1 \%$, we found no differences between patients and controls. Moreover, we also found no differences in the frequency of either SNP in the SOCS3 gene. To the best of our knowledge, these SNPs have never been tested with regard to RA in Caucasians. We found a lower frequency of genotype GA in SOCS3 rs4969168 in a overdominant model in RF-positive patients. Fang et al. [26] reported that genotype AG in rs4969168 showed the significant association with infantile asthma. Mentioned variant has had a higher frequency in patients compared to controls and genotypes AG and GG were associated with increased risk of asthma development. Both RA and asthma have a different pathogenesis; however it may be important to pay attention to genetic models analysis and their association with disease. Yan et al. [27] reported potential biological function of SOCS3 rs4969170. Discussed SNP was associated with elevated mRNA and protein expression in the patients with Graves' disease. They found that individuals with AA genotype have had an increased levels of mRNA and protein compared to carriers of GG genotype. Similar finding are demonstrated by Zheng et al. [15]. They reported increased levels of SOCS3 mRNA in insulin-resistant carriers of genotype AA. Both SNPs, rs4969168 and 4969179, are in linkage disequilibrium. Due to limited number of individuals haplotype analysis was out of the scope of this study; however this fact may be useful for further studies. Taken together, we found that SNPs with rs4969168 and rs4969170 may not be useful molecular markers related to RA.

DNA methylation in the SOCS3 gene may also not be useful as an epigenetic marker of disease in whole blood, but perhaps a focus on other epigenetic regulations, such as microRNA expression or histone modification in relation to this gene, may provide more valuable information.

The IL6R gene has long been a subject of interest among researchers, especially in the context of potential therapy using IL-6R antibodies [28]. For the IL6R gene we designed primers flanking the important regulatory region for TF IRF5. IRF5 is an important molecule responsible for transcription [18] and is associated with acute and chronic inflammation [29] as well as probability of being considered as epigenetic marker of RA [30]. In this gene we also found no differences between patients with RA and controls; all patients had fully unmethylated DNA. In contrast, de la Rica et al. [28] have found differences in the methylation pattern between DNA from rheumatoid arthritis synovial fibroblasts (RASFs) and osteoarthritis synovial fibroblasts (OASFs). Those from RA were hypomethylated in RASFs with respect to OASFs. IL-6R and its ligand play a key role in RA pathogenesis, including joint destruction, so it may be more useful to investigate the differences in DNA methylation in synovial tissue compared to in whole blood, as was done in our study. Moreover, the lack of differences in whole blood may be explained by the fact that IL-6R is distributed on the surface of most cells, and regulation of its expression in whole blood may take place via other pathways. Limited proteolysis of IL-6R or alternative mRNA splicing may generate a sIL-6R, which may induce an IL-6 transsignaling process [8, 9]. Furthermore, Liu et al. [16] have found four $\mathrm{CpG}$ sites associated with the RA phenotype, which may suggest a possible impact of IL6R gene methylation in RA. That study focused on finding differences between single $\mathrm{CpG}$ sites. In our study we have focused on finding a critical regulatory region, such as a TF binding site. However, both our study and that conducted by Liu et al. were performed on whole blood, which we considered essential for later clinical use, as not every laboratory has the capacity to test material such as synovial tissue. Further DNA methylation testing between specific cells and tissue, as well as in different methylation loci, is necessary to better understand the role of epigenetic regulations in $I L 6 R$ expression. We also 
found no differences in the frequency of either SNP between RF-positive and RF-negative patients and ACPA-positive and ACPA-negative patients. Previous reports [11,31] have shown a possible association between IL6R polymorphisms and susceptibility to RA, as well as joint destruction in subjects with RA. Biological function of rs2228145 was reported by Garbers et al. [32]. Variant allele was associated with twofold increased level of sIL6R in serum and was related to reduced production of CRP induced by IL6. Moreover, van Dongen et al. [11] reported that $\mathrm{C}$ allele reduces susceptibility to RA. Revez et al. [33] confirmed the impact of rs 2228145 on increased levels of sIL6R. Moreover, they reported that each copy of Tallele in rs4129267 increased the level of serum sIL6. Both SNPs were also in a strong linkage disequilibrium. As was mentioned above, haplotype analysis was out of scope of this study, but additional analysis related to these SNPs is required. To the best of our knowledge, we have demonstrated for the first time a lack of association between these SNPs with rs4129267 and rs2228145 and RF-positivity and ACPApositivity. It is difficult to compare our data with previous reports, and the power of analysis of our study is limited by the small group size.

A major limitation of determination of DNA methylation is the test material. We tested frozen whole blood and we used a single primer set to evaluate potential relationships between RA development and DNA methylation. A deeper analysis could be performed by pyrosequencing of a whole SOCS3 and IL6R promoters or analysis of sorted blood mononuclear cells subpopulations. Also methylation analysis of more specific tissue, like synovial may provide additional information about epigenetic regulation of SOCS3 and IL6R genes. It is important to mention that our study shows a basic data with low number of individuals enrolled to genotyping; thus interpretation of the results is limited (please refer to confidence intervals in Supplementary Tables S2-S4 and S6-S8). Genotyping analysis on a larger cohort is necessary to confirm our data. Despite that data shown in the manuscript were an initial data, they may stimulate further studies.

\section{Conclusions}

To conclude, SOCS3 and IL6R are critical genes involved in the IL-6 signaling pathway. In whole blood, no methylation signals were obtained from both genes. Deeper analysis of more specific material, including subpopulations of blood mononuclear cells or synovial tissue, may be useful to determine their methylation status and relationships with RA.

\section{Data Availability}

The data used to support the findings of this study are available from the corresponding author upon request.

\section{Conflicts of Interest}

The authors declare that there are no conflicts of interest regarding the publication of this paper.

\section{Supplementary Materials}

Table S1: genotypes and alleles distribution. Table S2: distribution of genotypes in different genetic models between patients and controls. Table S3: distribution of genotypes in different genetic models between rheumatoid factor positive and rheumatoid factor negative patients. Table S4: distribution of genotypes in different genetic models between anticitrullinated protein antibodies positive and anticitrullinated protein antibodies negative patients. Table S5: genotypes and alleles distribution. Table S6: distribution of genotypes in different genetic models between patients and controls. Table S7: distribution of genotypes in different genetic models between rheumatoid factor positive and rheumatoid factor negative patients. Table S8: distribution of genotypes in different genetic models between anticitrullinated protein antibodies positive and anticitrullinated protein antibodies negative patients. Figure S1: linkage disequilibrium between rs4969168 and rs4969170. Figure S2: linkage disequilibrium between rs4129267 and rs2228145. (Supplementary Materials)

\section{References}

[1] S. Li, Y. Yu, Y. Yue, Z. Zhang, and K. Su, "Microbial infection and rheumatoid arthritis," Journal of Clinical \& Cellular Immunology, vol. 4, no. 6, p. 174, 2013.

[2] D. Aletaha, T. Neogi, A. J. Silman et al., "2010 rheumatoid arthritis classification criteria: an American College of Rheumatology/European League against rheumatism collaborative initiative," Arthritis \& Rheumatism, vol. 62, no. 9, pp. 2569-2581, 2010.

[3] I. B. McInnes and G. Schett, "The pathogenesis of rheumatoid arthritis," New England Journal of Medicine, vol. 365, no. 23, pp. 2205-2219, 2011.

[4] I. B. McInnes and G. Schett, "Cytokines in the pathogenesis of rheumatoid arthritis," Nature Reviews Immunology, vol. 7, no. 6, pp. 429-442, 2007.

[5] C. Luo, P. Hajkova, and J. R. Ecker, "Dynamic DNA methylation: in the right place at the right time," Science, vol. 361, no. 6409, pp. 1336-1340, 2018.

[6] S. Domcke, A. F. Bardet, P. Adrian Ginno, D. Hartl, L. Burger, and D. Schübeler, "Competition between DNA methylation and transcription factors determines binding of NRF1," Nature, vol. 528, no. 7583, pp. 575-579, 2015.

[7] J. Wielińska, M. Dratwa, J. Świerkot et al., "Interleukin-6 gene polymorphism is associated with protein serum level and disease activity in Polish patients with rheumatoid arthritis," HLA, vol. 92, no. Suppl 2, pp. 38-41, 2018.

[8] J. J. Babon, L. N. Varghese, and N. A. Nicola, "Inhibition of IL6 family cytokines by SOCS3," Seminars in Immunology, vol. 26, no. 1, pp. 13-19, 2014.

[9] J.-M. Dayer and E. Choy, "Therapeutic targets in rheumatoid arthritis: the interleukin-6 receptor," Rheumatology, vol. 49, no. 1, pp. 15-24, 2010.

[10] F. Cunningham, P. Achuthan, W. Akanni et al., "Ensembl 2019," Nucleic Acids Res, vol. 47, no. D1, pp. D745-D751, 2019.

[11] J. van Dongen, R. Jansen, D. Smit et al., "The contribution of the functional IL6R polymorphism rs2228145, eQTLs and other genome-wide SNPs to the heritability of plasma sIL-6R levels," Behavior Genetics, vol. 44, no. 4, pp. 368-382, 2014. 
[12] G. A. Hawkins, M. B. Robinson, A. T. Hastie et al., "The IL6R variation Asp(358)Ala is a potential modifier of lung function in subjects with asthma," Journal of Allergy and Clinical Immunology, vol. 130, no. 2, pp. 510-515.e1, 2012.

[13] E. Ekelund, A. Sääf, M. Tengvall-Linder et al., "Elevated expression and genetic association links the SOCS3 gene to atopic dermatitis," The American Journal of Human Genetics, vol. 78, no. 6, pp. 1060-1065, 2006.

[14] F. Vidal, M. López-Dupla, M. Laguno et al., "Pharmacogenetics of efficacy and safety of HCV treatment in HCV-HIV coinfected patients: significant associations with IL28B and SOCS3 gene variants," PLoS One, vol. 7, no. 11, Article ID e47725, 2012.

[15] Y.-Y. Zheng, L.-F. Wang, X.-H. Fan et al., "Association of suppressor of cytokine signalling 3 polymorphisms with insulin resistance in patients with chronic hepatitis C," Journal of Viral Hepatitis, vol. 20, no. 4, pp. 273-280, 2013.

[16] Y. Liu, M. J. Aryee, L. Padyukov et al., "Epigenome-wide association data implicate DNA methylation as an intermediary of genetic risk in rheumatoid arthritis," Nature Biotechnology, vol. 31, no. 2, pp. 142-147, 2013.

[17] R. Dreos, G. Ambrosini, R. C. Périer, and P. Bucher, "The eukaryotic promoter database: expansion of EPDnew and new promoter analysis tools," Nucleic Acids Research, vol. 43, no. D1, pp. D92-D96, 2015.

[18] S. T. Smale, "Transcriptional regulation in the immune system: a status report," Trends in Immunology, vol. 35, no. 5, pp. 190-194, 2014.

[19] L.-C. Li and R. Dahiya, "MethPrimer: designing primers for methylation PCRs," Bioinformatics, vol. 18, no. 11, pp. 1427-1431, 2002.

[20] M. J. Machiela and S. J. Chanock, "LDlink: a web-based application for exploring population-specific haplotype structure and linking correlated alleles of possible functional variants: Fig. 1," Bioinformatics, vol. 31, no. 21, pp. 3555-3557, 2015.

[21] B. Carow and M. E. Rottenberg, "SOCS3, a major regulator of infection and inflammation," Front Immunol, vol. 5, no. 1, p. 58, 2014.

[22] H. Wang, M. T. Maurano, H. Qu et al., "Widespread plasticity in CTCF occupancy linked to DNA methylation," Genome Research, vol. 22, no. 9, pp. 1680-1688, 2012.

[23] Y. Li, J. Deuring, M. P. Peppelenbosch, E. J. Kuipers, C. de Haar, and C. J. van der Woude, "IL-6-induced DNMT1 activity mediates SOCS3 promoter hypermethylation in ulcerative colitis-related colorectal cancer," Carcinogenesis, vol. 33, no. 10, pp. 1889-1896, 2012.

[24] T. Yoshikawa, A. Takata, M. Otsuka et al., "Silencing of microRNA-122 enhances interferon- $\alpha$ signaling in the liver through regulating SOCS3 promoter methylation," Scientific Reports, vol. 2, no. 1, p. 637, 2012.

[25] P. Isomaki, T. Alanara, P. Isohanni et al., "The expression of SOCS is altered in rheumatoid arthritis," Rheumatology, vol. 46, no. 10, pp. 1538-1546, 2007.

[26] Y. Fang, X. Ren, and Z. Feng, "Genetic correlation of SOCS3 polymorphisms with infantile asthma: an evidence based on a case-control study," International Journal of Clinical and Experimental Pathology, vol. 8, no. 8, pp. 9586-9591, 2015.

[27] R. Yan, J. Yang, P. Jiang et al., "Genetic variations in the SOCS3 gene in patients with Graves' ophthalmopathy," Journal of Clinical Pathology, vol. 68, no. 6, pp. 448-452, 2015.

[28] L. de la Rica, J. M. Urquiza, D. Gómez-Cabrero et al., "Identification of novel markers in rheumatoid arthritis through integrated analysis of DNA methylation and
microRNA expression," Journal of Autoimmunity, vol. 41, pp. 6-16, 2013.

[29] M. Weiss, A. J. Byrne, K. Blazek et al., "IRF5 controls both acute and chronic inflammation," Proceedings of the National Academy of Sciences, vol. 112, no. 35, pp. 11001-11006, 2015.

[30] M. Cieśla, B. Kolarz, M. Majdan, and D. Darmochwał-Kolarz, "IRF5 promoter methylation as a new potential marker of rheumatoid arthritis," Polish Archives of Internal Medicine, vol. 129, pp. 370-376, 2019.

[31] M. Lopez-Lasanta, A. Julià, J. Maymó et al., "Variation at interleukin-6 receptor gene is associated to joint damage in rheumatoid arthritis," Arthritis Research \& Therapy, vol. 17, no. 1, p. 242, 2015.

[32] C. Garbers, N. Monhasery, S. Aparicio-Siegmund et al., "The interleukin-6 receptor Asp358Ala single nucleotide polymorphism rs2228145 confers increased proteolytic conversion rates by ADAM proteases," Biochimica et Biophysica Acta (BBA)-Molecular Basis of Disease, vol. 1842, no. 9, pp. 1485-1494, 2014.

[33] J. A. Revez, L. Bain, B. Chapman et al., "A new regulatory variant in the interleukin-6 receptor gene associates with asthma risk," Genes \& Immunity, vol. 14, no. 7, pp. 441-446, 2013. 